\title{
BMJ Open Effectiveness of the Diagnose-Intervene- Verify-Adjust (DIVA) model for integrated primary healthcare planning and performance improvement: an embedded mixed methods evaluation in Kaduna state, Nigeria
}

Ejemai Amaize Eboreime, ${ }^{1,2}$ Nonhlanhla Nxumalo, ${ }^{2}$ Rohit Ramaswamy, ${ }^{3}$ Latifat Ibisomi, ${ }^{4,5}$ Nnenna Ihebuzor, ${ }^{6}$ John Eyles ${ }^{2,7}$

To cite: Eboreime EA Nxumalo N, Ramaswamy R, et al. Effectiveness of the Diagnose-InterveneVerify-Adjust (DIVA) model for integrated primary healthcare planning and performance improvement: an embedded mixed methods evaluation in Kaduna state, Nigeria. BMJ Open 2019;9:e026016. doi:10.1136/ bmjopen-2018-026016

- Prepublication history and additional material for this paper are available online. To view these files, please visit the journal online (http://dx.doi. org/10.1136/bmjopen-2018026016).

Received 15 August 2018 Revised 11 January 2019 Accepted 14 February 2019

Check for updates

(c) Author(s) (or their employer(s)) 2019. Re-use permitted under CC BY-NC. No commercial re-use. See rights and permissions. Published by BMJ.

For numbered affiliations see end of article.

Correspondence to Dr Ejemai Amaize Eboreime; ejemaim@gmail.com

\section{ABSTRACT}

Objectives This study evaluates the real-world effectiveness of Diagnose-Intervene-Verify-Adjust (DIVA), an innovative quality improvement mode, in improving primary healthcare (PHC) bottlenecks impeding health system performance in Kaduna, a northern Nigerian state. Design An embedded mixed method study design involving participant observation.

Setting PHCs in 23 local government areas of Kaduna state, Nigeria.

Participants $138 \mathrm{PHC}$ managers across the state (PHC directors and programme managers in the 23 local governments).

Intervention DIVA is a four-step improvement model in which 'Diagnose' identifies constraints to effective coverage, 'Intervene' develops/implements action plans addressing constraints, while 'Verify/Adjust' monitor performance and revise plans.

Primary and secondary outcome measures The model, as adapted in Nigeria, is designed to evaluate and improve the availability of health commodities, human resources, geographical accessibility, acceptability, continuous utilisation and quality of four PHC interventions (immunisation, integrated management of childhood illnesses, antenatal care and skilled birth attendance).

Results 183 bottlenecks were identified by local government teams across all interventions in 2013. 41\% of bottlenecks concern human resources. Geographical access and availability of commodities ranked least. Availability of commodities was the most improved determinant although among the least constrained, probably indicating skewed implementation of operational plans. 1562 activities were planned to address identified bottlenecks in the state, of which only $568(36 \%)$ were completely implemented

Conclusion Our study demonstrates that PHC planning using the DIVA model can potentially improve health system performance. However, effective implementation is critical and may require some central government oversight.
Strengths and limitations of this study

- This study uses an uncontrolled before and after design for assessing change in identified bottlenecks.

- The design is constrained in attributing observed improvement to the intervention but was, however, most suitable given that all local governments in the state are implementing Diagnose-Intervene-Verify-Adjust.

- Participant observation methods are prone to the Hawthorne effect.

- Given that this is an embedded real-world continuous improvement intervention, the Hawthorne effect is a desirable if positive and sustained.

- We found this design very useful and easy-to-use for lower level operational managers in low- and middle-income countries implementing/evaluating health system improvement initiatives, particularly in district/decentralised health systems.

\section{BACKGROUND}

Introduction

Attaining universal health coverage (UHC) requires systems capable of ensuring that required interventions and services are effectively delivered to populations in need. Primary healthcare (PHC) provides an appropriate platform for integrating health system components towards UHC. ${ }^{1}$ While selective PHC services usually offer a quick win approach to disease control through verticalised interventions such as immunisation and malaria control programmes, integrated health system strengthening is being advocated as a more efficient and effective strategy for improved health system performance. ${ }^{23}$ Substantial knowledge exists on causes of ill-health alongside interventions to address them, however how to implement 
these interventions is far less understood. ${ }^{4}$ This is typical of complex health systems characterised by many actors and interest groups (governmental and non-governmental) operating at different levels. ${ }^{5}$ Lower levels of decentralised health systems are known to pose implementation challenges in low- and middle-income countries (LMICs) largely due to weak capacity for governance as well as political constraints. ${ }^{6-8}$ Several methods have been implemented to improve PHC performance in LMICs. Most common of these approaches include supportive supervision, mentoring, tools and aids, quality improvement methods and coaching. ${ }^{9}$ These approaches have largely focused on health facilities and are mostly vertical (focusing on one intervention). ${ }^{79}$ A systematic review of quality improvement strategies for improving maternal and child health in LMICs revealed a limited number of studies involved integrated approach to PHC. ${ }^{10}$ In this paper, we examine the effectiveness of an innovative model for improving integrated PHC performance as implemented in Kaduna, a northern Nigerian state.

The Diagnose-Intervene-Verify-Adjust (DIVA) model was designed for systematically identifying and resolving health systems bottlenecks, particularly in decentralised LMIC contexts. ${ }^{11}$ The intervention theory, as described in the methods section, postulates that implementation of DIVA should improve health systems performance by facilitating prompt identification and response to health systems bottlenecks. However, in real-world contexts, the extent to which this can be achieved is not established. Implementation theorists believe that the effectiveness of interventions is subject to contextual variations, thus similar results may not be expected across all settings. ${ }^{12}$ Consequently, this paper evaluates the effectiveness of DIVA as a model for improving health system performance through integrated PHC operational planning in Kaduna, Nigeria.

The DIVA model was introduced by Unicef in nine sub-Saharan African countries (Botswana, Democratic Republic of Congo, Mali, Malawi, Niger, Nigeria, Sierra Leone, Uganda and Zambia). ${ }^{13}$ While there has been some success in terms of DIVA providing evidence for policy making in these countries, ${ }^{11}{ }^{13}$ there has been no effectiveness study of DIVA implementation to our knowledge. 'Effectiveness' here refers to how the intervention affects health systems outcomes when implemented in real-world (uncontrolled) environment. Thus, it reflects how contextual factors (such as the political economy, implementer capacity and discretion, stakeholder influences, etc) may enhance or inhibit the expected outcome of the intervention. ${ }^{14}{ }^{15}$ Given the contextual diversities of these countries particularly with respect to political governance (all except Nigeria have a centralised government), ${ }^{8}$ our study provides unique insight to implementing DIVA in a politically decentralised system. Thus, lessons from this implementation research may be used to inform adaptation of DIVA in other similar politically decentralised LMIC contexts.

\section{Study context}

Nigeria's health system is anchored on a PHC structure known as the Ward Health System (WHS) ${ }^{16}$ The WHS is an adaptation of the WHO's District Health System where political wards of the local governments (LGs) (the smallest political governance units) double as the operational units for PHC. ${ }^{17}$ This design aims to strengthen community participation in health system governance as envisaged in the Alma-Ata PHC declaration of 1978. ${ }^{18}$ The WHS operates a primarily community-based management structure which functions through the Ward Development Committees (WDCs) and Village Development Committees (VDCs) at the ward and village levels respectively. Each WDC consists mostly of chairmen of the various VDCs under its jurisdiction while the VDCs consist of respectable members of the communities and representatives of various community-based interest groups and strata (eg, women, youth and occupational groups). ${ }^{19}$ The functions of these committees include identifying, planning interventions and mobilising resources to meet health and social needs of the communities, supporting and monitoring the implementation of work plans and activities of community-based and health facility workers, support maintenance of the Ward Health Centres as well as serve as the linkage between the communities and the government/other partners. ${ }^{17}$ Although the DIVA model is designed to strengthen this model, ${ }^{11}$ in practice community participation has been rather very passive. ${ }^{20}$

This study was conducted in Kaduna, one of Nigeria's 37 states/territories. Kaduna is home to about $7915487^{21}$ people distributed across 23 local government areas and 255 political wards. About 1523 (98\%) of the 1560 health facilities in Kaduna are PHC facilities. ${ }^{22}$

\section{METHODS}

\section{The DIVA model}

DIVA is a variant of the Plan-Do-Study-Act cycle designed to improve performance in complex macro-health systems, particularly the district health system. ${ }^{11}{ }^{23}$ The model aims to build the capacity of LG health managers to assess, analyse, act and be accountable for equitable service delivery and to strengthen decentralised health systems. Four principles guide the implementation of DIVA- strong government leadership and ownership; flexibility and adaptability to local programmes, building on what exists; community involvement and engagement and supportive (technical and financial) process from civil society, private sector and development partners. ${ }^{11}$ Kaduna state implements DIVA in quarterly cycles for each LG and annual reviews are conducted at the state level which feed into existing health sector annual budgeting and planning cycles. These phases overlap in practice. ${ }^{24}$ The phases of DIVA are described below:

\section{Diagnose phase}

A modified Tanahashi model, described by O'Connell and Sharkey, is used during the diagnose phase of the 


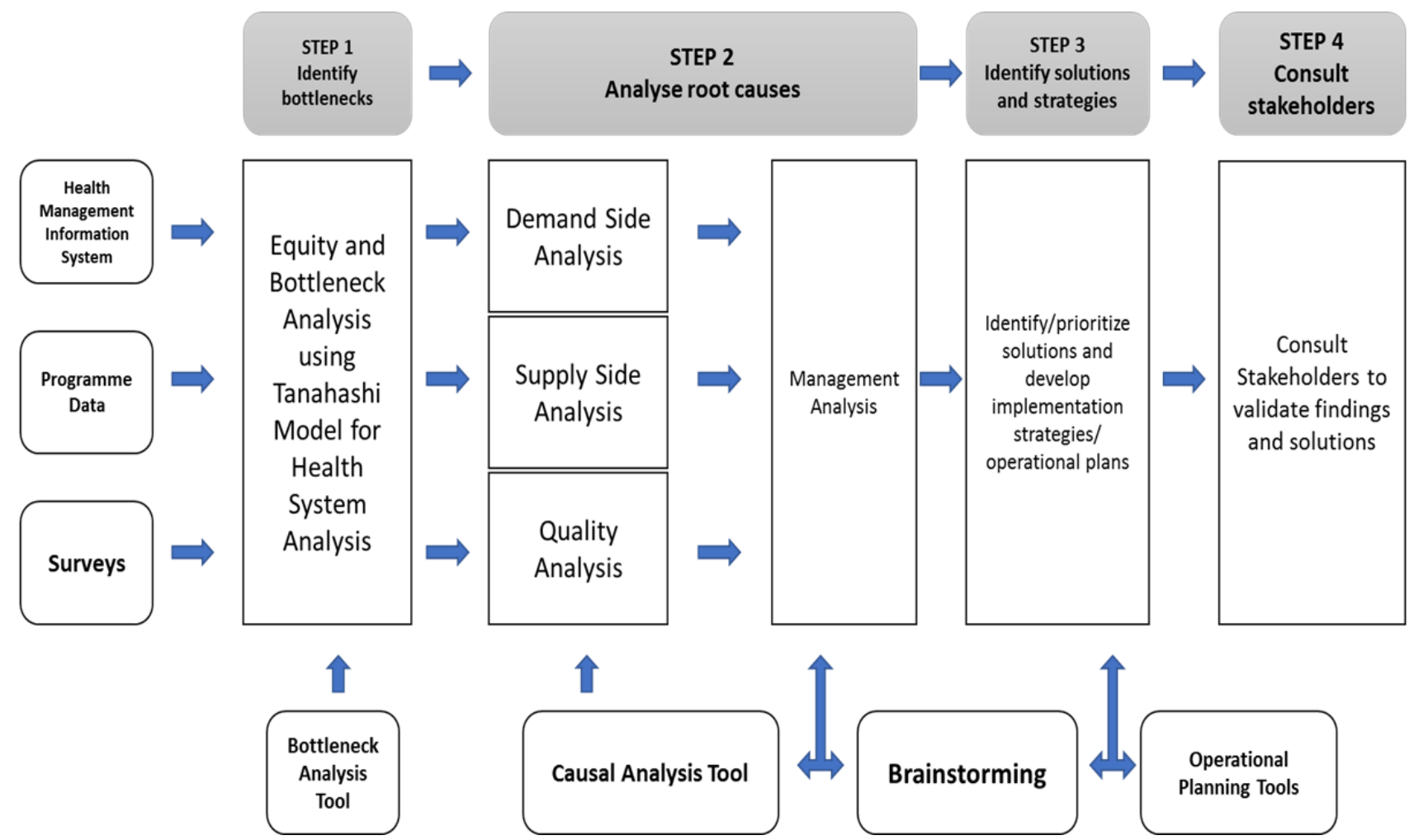

Figure 1 Framework for implementation of the 'Diagnose' phase (adapted from Unicef and Management Science for Health $\left.(\mathrm{MSH})^{11}\right)$.

PHC reviews to assess health systems bottlenecks at the LG level. ${ }^{1325}$ Six determinants of quality or 'effective coverage' of interventions are measured: availability of essential health commodities, availability of human resources, accessibility of distribution points for the interventions (geographical access), initial utilisation (acceptability) of interventions, continuous utilisation (contact) of interventions and quality of interventions delivered. The first three determinants represent the supply side while the others are demand side determinants. Health systems bottlenecks are identified as constraints to full functioning of each determinant which impacts on effective/quality coverage of the intervention. ${ }^{13}$

A pre-implementation training of LG PHC management teams on bottleneck analysis methodology was conducted in 2012. ${ }^{26}$ Thereafter, during the PHC reviews we provide technical guidance to the teams to carry out this diagnosis using routine data (and data from other sources eg demographic and health surveys) analysed on a MS-Excel based Bottleneck Analysis tool developed by the National PHC Development Agency (NPHCDA). ${ }^{24}$ The LG teams are then supported to identify bottlenecks inhibiting optimal effective coverage with respect to each tracer intervention. This training and technical support was embedded into the DIVA process to ensure optimal implementation fidelity by mitigating lower-level discretion commonly observed in multi-level governance contexts. ${ }^{727-29}$

The tool calculates coverage for each determinant using routine data inputted from the health management information system as numerators and the national population census data as denominators. Graphs are automatically developed for analyses. The difference between target coverage and observed coverage for each determinant is identified as a measure of the bottleneck. ${ }^{1324} 2530$

Using techniques and tools like brainstorming, ' 5 Whys' technique, ${ }^{31}$ affinity and driver diagrams, the teams are guided to identify immediate, proximate and distal causes of identified bottlenecks (S1). This step is known as root cause/causal analysis (figure 1).

Intervene phase

Following step 1, LG teams are guided to identify plausible solutions to these bottlenecks with specific quality/ coverage targets for each quarter. Thereafter, proffered solutions are converted into action plans (S1) which are incorporated in annual health operational plans and budgets following stakeholder consultation (eg, the State PHC Development Agency chief executive, LG chairperson and ministries of health and finance). This is followed by implementation of the planned activities.

\section{Verify phase}

During this phase, the implementation of planned activities is monitored through existing supportive supervision, monitoring and evaluation mechanisms year-round. This helps early detection of deviation or lag while also ensuring implementation fidelity of planned activities. Quarterly diagnostic cycles further enhance verification. Supportive supervision includes quarterly visits from state 


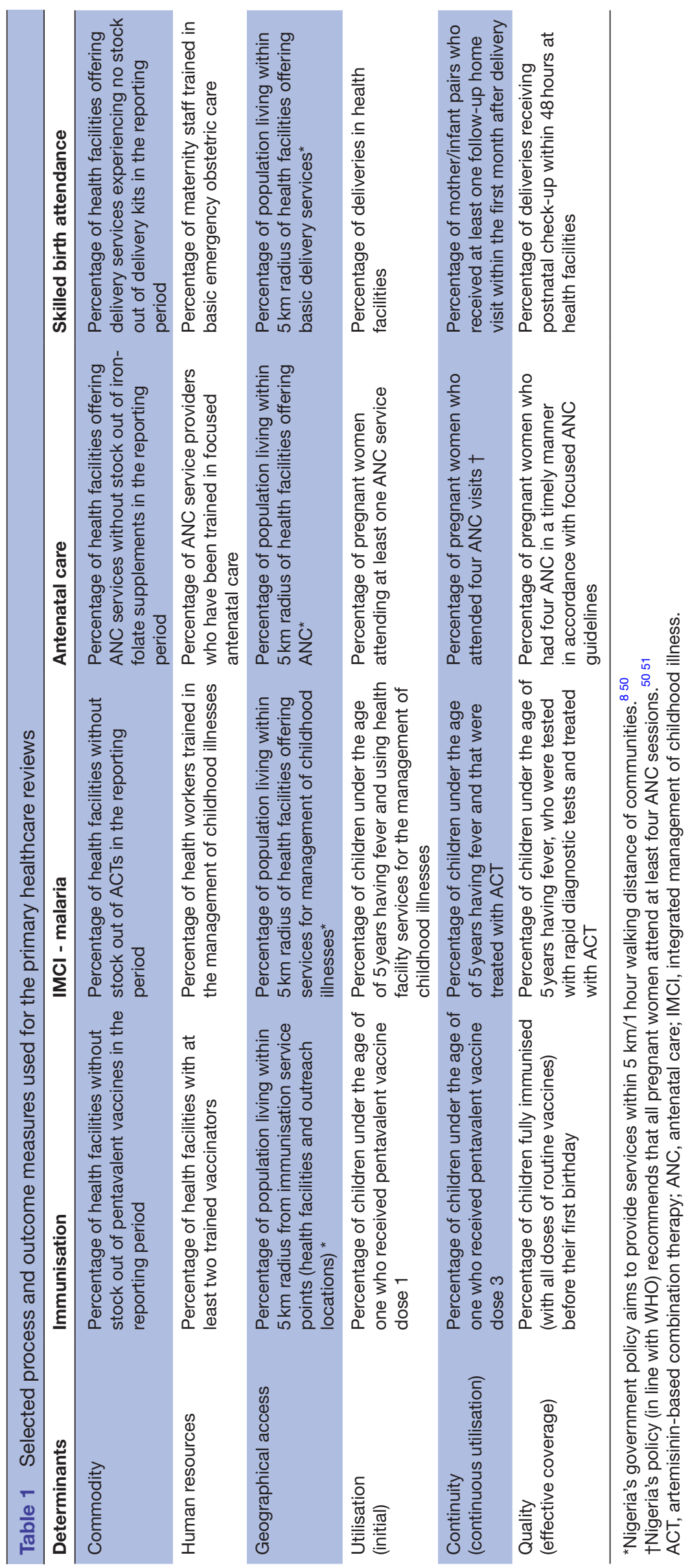




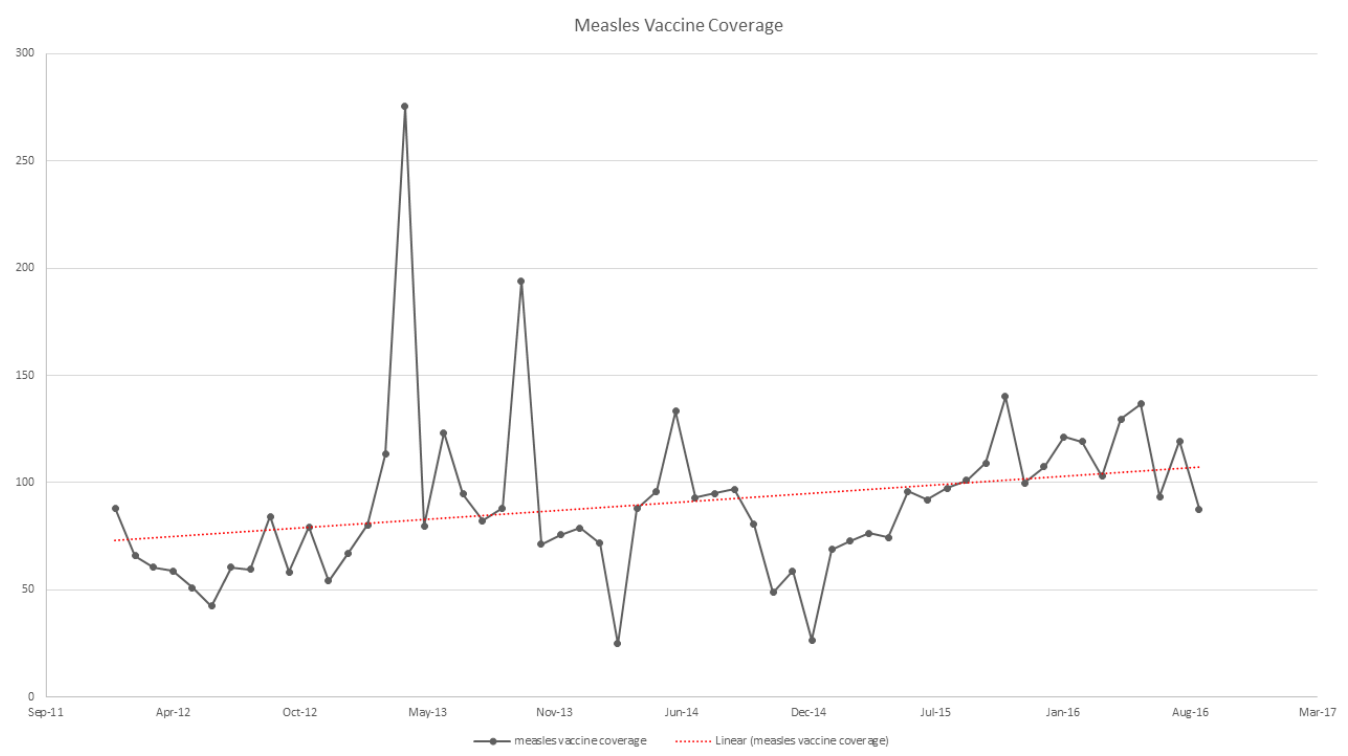

Figure 2 Trend - coverage of measles vaccine (monthly).

to LGs and from LGs to health facilities to supervise and aid frontline health workers as they implement activities planned out for each intervention.

\section{Adjust phase}

At any point during verification, implementation challenges identified are addressed to ensure interventions are carried out as planned and are on track towards attaining targets within stipulated time frames.

\section{DIVA implementation process in Kaduna}

Eight state and LG teams (PHC managers) were trained on the methodology of and guided on the Diagnose and Intervene steps to obtain a baseline in 2013. These managers include the PHC directors and programme managers at both levels. Thereafter technical support was provided during the annual reviews conducted in March each year. The reviews focused on determinants for availability of health commodities, human resources for health, geographical accessibility, initial utilisation, continuous utilisation and quality coverage of four PHC tracer interventions (immunisation, Integrated Management of Childhood Illnesses (IMCI), antenatal care and skilled birth attendance). These tracer interventions were selected by stakeholders in the health sector using the following criteria: 'Data is available for the six coverage determinants; the tracer is an internationally recommended intervention with proven and quantified efficacy; the tracer is representative of other indicators within its intervention group in terms of facing similar health systems constraints at the chosen service delivery level, for accurate assessment of costs in overcoming bottlenecks. ${ }^{32}$

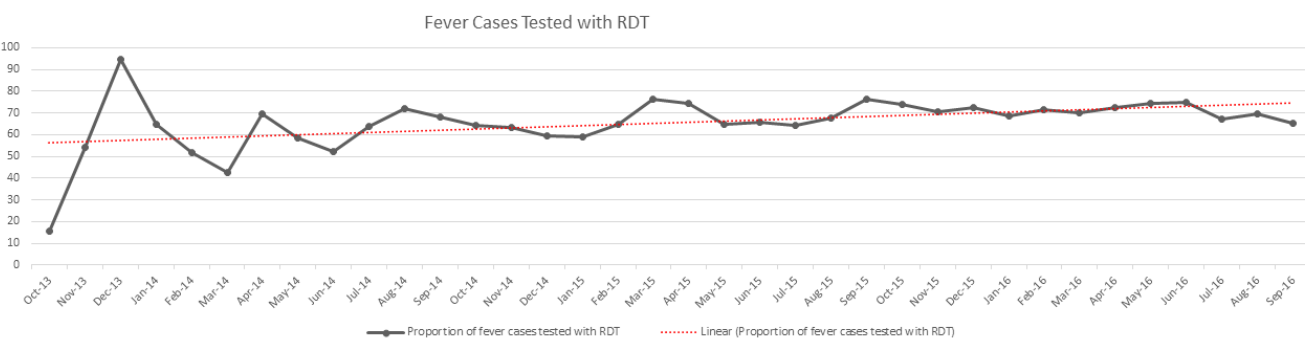

Clinical Malaria Treated with ACT

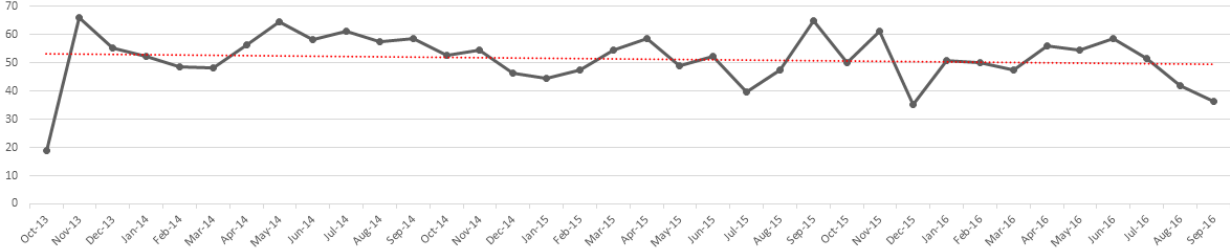

Figure 3 Trend - outcome of management of febrile illnesses (monthly). ACT, artemisinin-based combination therapy; RDT, rapid diagnostic testing. 

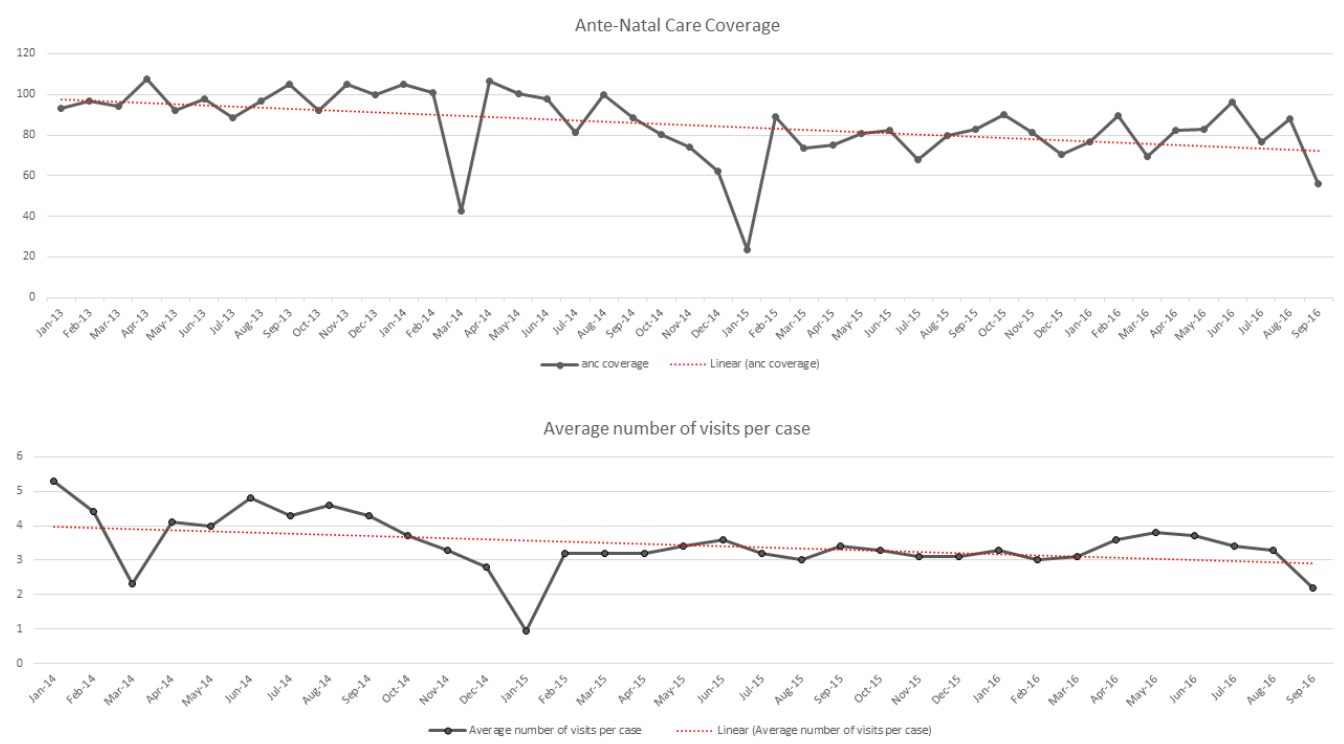

Figure 4 Trends - outcomes of antenatal care.

LG health management teams (PHC directors and programme managers) were coached and supervised as they utilised routine data collected from their LGs to analyse health systems constraints, develop and implement evidence-informed plans to address them and improve performance. Each of Kaduna state's 23 LGs have six PHC managers (one PHC director and five programme managers) involved with DIVA. A total of 138 across the state therefore constituted the study population. Field notes were taken, and reports developed from each LG detailing bottlenecks identified, causal analysis and action/operational plans for each year. Draft reports were circulated to all LGs for confirmation and inputs towards the final documents (which were also endorsed by all LGs).

\section{Study design}

We evaluated the PHC reviews in Kaduna using an embedded a mixed method approach. The mixed approach was complementary such that qualitative data provided context and content to the changes in indicators measured using quantitative methods. ${ }^{33}$ Embedded

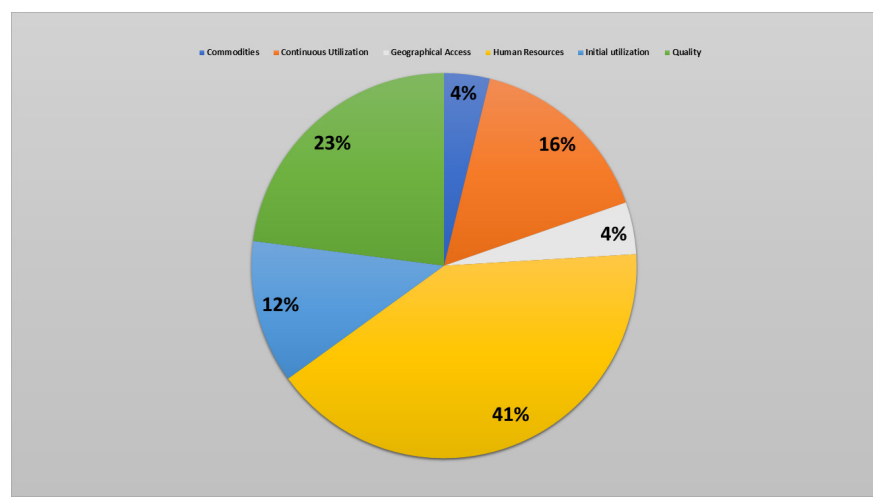

Figure 5 Distribution of identified bottlenecks across determinants of health system performance. research involves a partnership between researchers and decision-makers to facilitate co-production of knowledge towards evidence-informed policy and practice. ${ }^{34}{ }^{35}$ A moderate participant observation approach was employed such that the embedded researchers mostly acted as process facilitators for the state and LG teams. ${ }^{36} \mathrm{EAE}$ and NI were played dual roles as embedded researchers and national-level policy makers between 2013 and 2016. The process aligned with Howell's participant observation phases such that the researchers first established rapport with the participants (subnational PHC managers), then embedded themselves in the field as process facilitators, recorded observations as fieldnotes and finally conducted framework and narrative analyses of the information gathered. ${ }^{37}$ Detailed findings from these analyses are beyond the scope of this paper, but are published in other sub-studies within this research series. ${ }^{7026}$ However, collated outputs from the process inform the process description below as well as the 'causal analyses and planned action table' in the results section.

Furthermore, we quantitatively evaluated the effectiveness of DIVA by measuring improvements on selected indicators (table 1) developed by the NPHCDA and from the Health Management Information System. ${ }^{24}{ }^{32}$ Each LG team was instructed to identify two priority bottlenecks (constrained determinants) per intervention (one supply side and one demand side) using the MS-Excel bottleneck analysis tool described earlier. We followed up on actions planned to tackle these identified bottlenecks and their impact on reducing them between 2013 and 2016. This was done by extracting data from programme reports on how the planned activities were implemented. The level of implementation was categorised in a three-point ordinal scale (not implemented, partly implemented and completely implemented). The implementation data collated from all LGs was analysed using a pie-chart. 

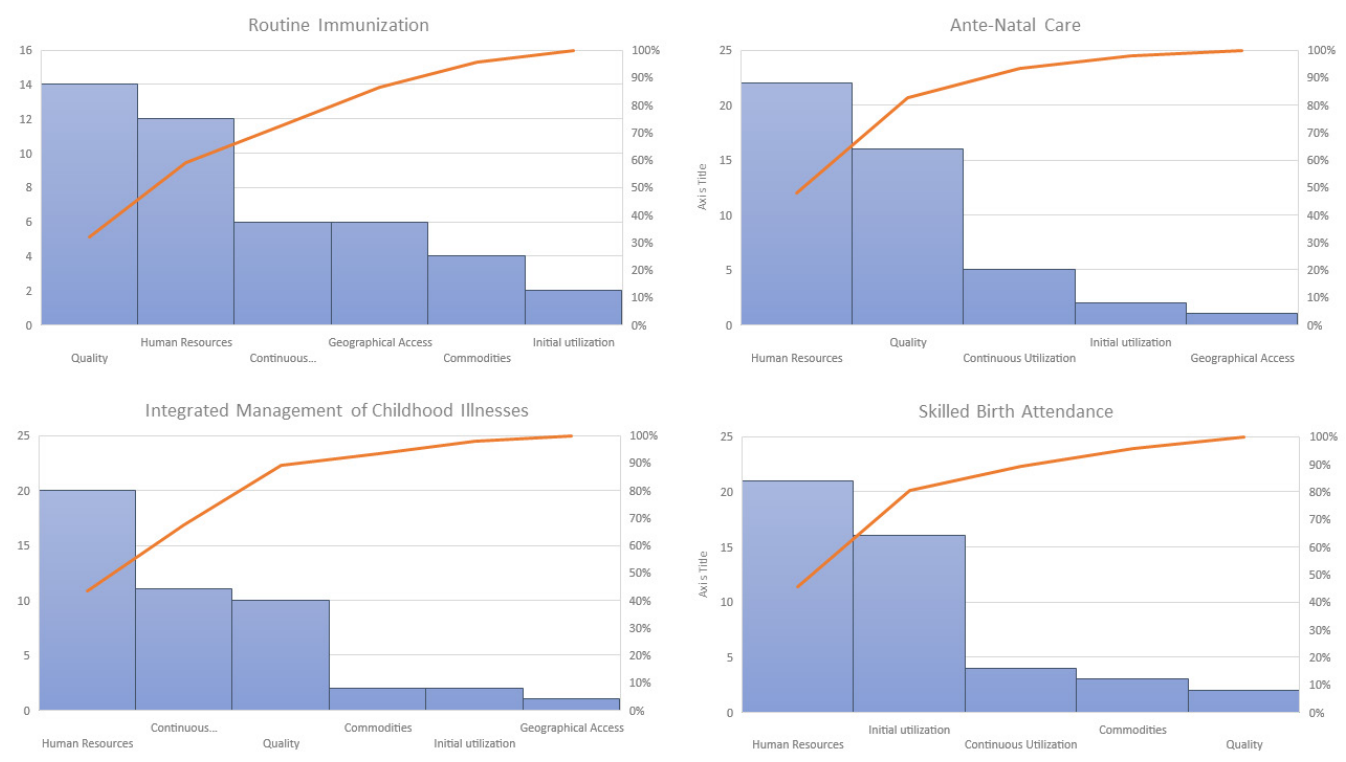

Figure 6 Pareto charts showing priority ranking of determinants with identified bottlenecks for each tracer intervention.

Coverage gap analyses were conducted on the prioritised bottlenecks to monitor improvements. The median performance values of each constrained determinant identified across the 23 LGs was determined both at baseline and post-implementation. Median values (rather than mean) were used as measures of central tendency to eliminate the effect of isolated extreme performance in some LGs. The change in bottlenecks are presented in bar charts. Health system performance measures were monitored using time-series charts which show trends in monthly coverage of selected outcome measures between 2013 and 2016. A trend analyses was conducted to monitor for possible improvements. The selected measures were based on proximate indicators from Nigeria's National Strategic Health Development Plan considered to have indirect but proximate relationships with the DIVA indicators. ${ }^{38}$ These are trends in measles vaccination coverage, management of febrile Illnesses using rapid diagnostic testing (RDT) and artemisinin-based combination therapy (ACT) for confirmed malaria cases, and attendance at antenatal care clinics.

\section{Patient and public involvement}

This study did not directly involve the patients, but rather an ecological approach using data from the Health Management Information System. The participatory action research approach involved the health system managers and planners who utilised the routine (secondary) data for decision making.

\section{RESULTS}

The results from this evaluation represent findings aggregated from 1523 out of 1560 health facilities distributed across all 23 LGs in Kaduna state.

\section{Trend of selected performance measures based on routine data}

First, we present trend analyses of selected outcomes; vaccination: measles vaccine coverage, antenatal care (ANC): coverage and average visits per client, IMCI: fever cases tested with RDT and clinical malaria treated with ACT. These outcomes were selected because they are proxy indicators of health systems performance associated with the various interventions in the national PHC review guidelines. ${ }^{24}$

Figures 2-4 show that although improvement is observed with some outcome indicators (measles vaccination and fever cases tested with RDT), decline was observed with others.

\section{Bottleneck analysis and action plan implementation}

We now present findings from the baseline diagnosis in 2013 with priority ranking of bottlenecks and root cause analysis across the various interventions and causal analysis. Thereafter we demonstrate on bar charts how these bottlenecks have changed between 2013 and 2016. Lastly, we illustrate implementation gaps in action plans developed to address the bottlenecks.

A total of 183 bottlenecks were identified by the 23 LG teams across all tracer interventions in 2013. Figure 5 shows the distribution of these bottlenecks across the modified Tanahashi determinants. Most $(41 \%)$ bottlenecks identified relate to human resource challenges, while geographical access and availability of commodities ranked least (4\% respectively). Figure 6 disaggregates these findings per tracer intervention using Pareto charts.

Table 2 shows the common bottlenecks for each intervention as well as their probable causes as identified by the LG teams. Online supplementary material S1 contains an example of integrated evidence-informed operational plans developed by the teams during the PHC reviews to address these constraints. 


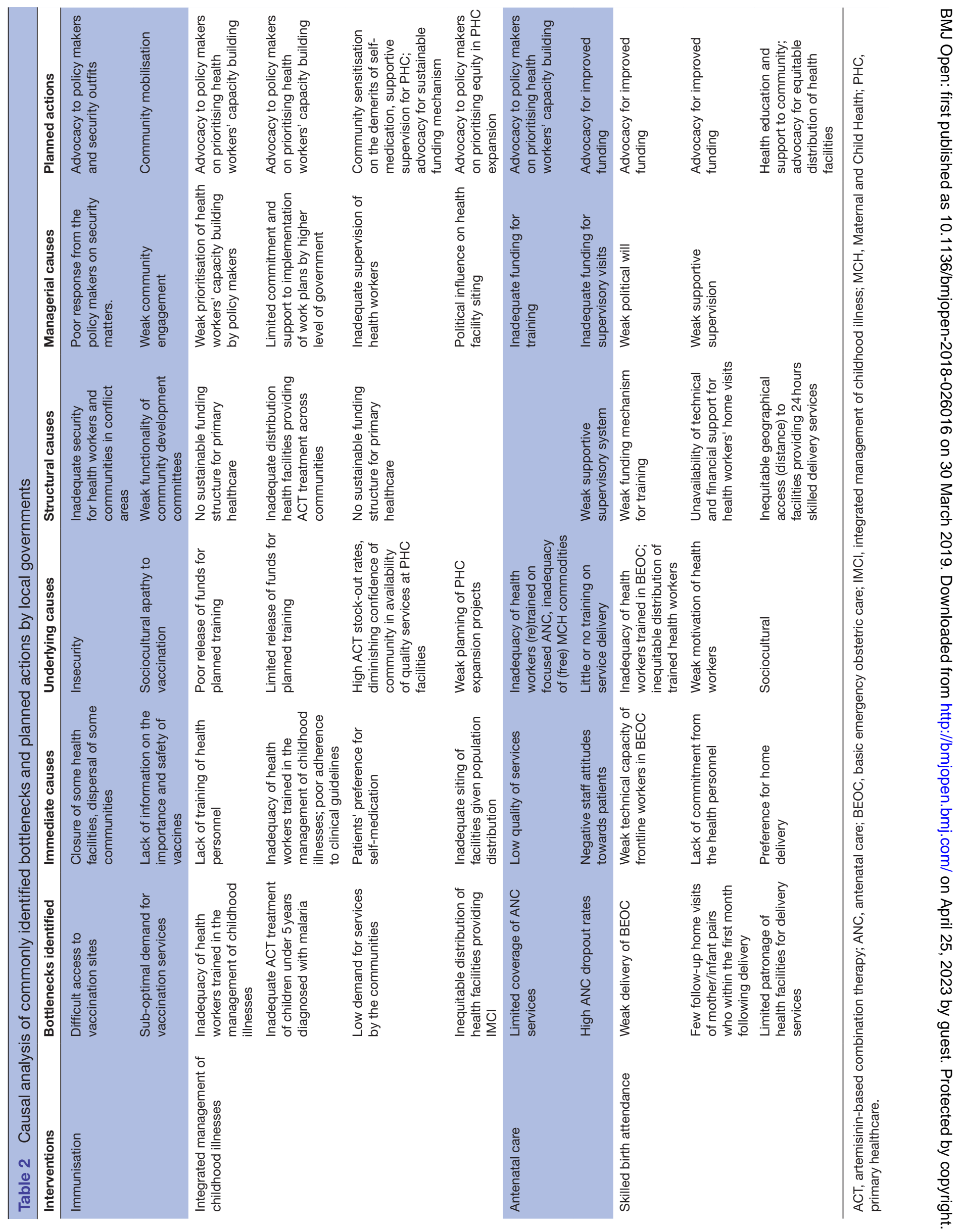



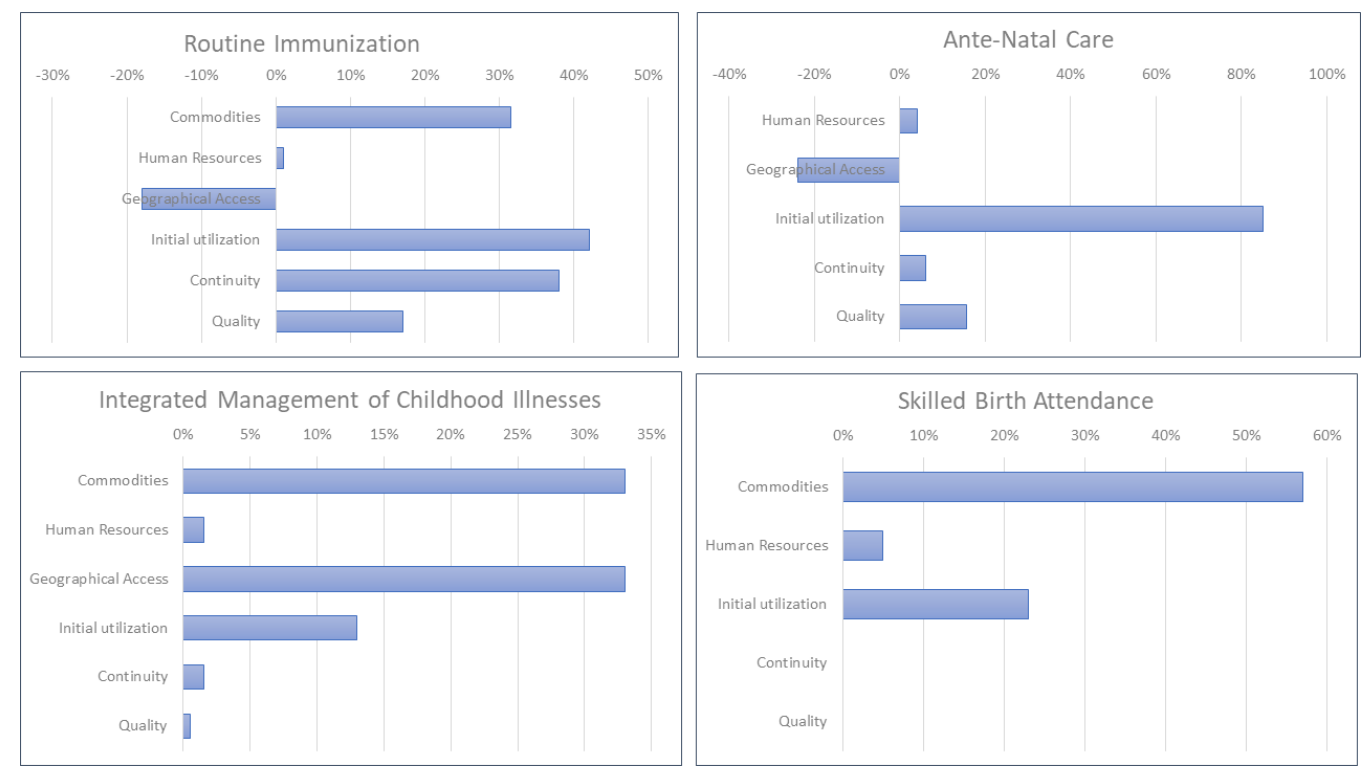

Figure 7 Bar charts showing changes in median values of indicators for each intervention between 2013 and $2016^{*}\left({ }^{*}\right.$ some determinants were not identified by the teams as having priority bottlenecks in 2013).

Figure 7 measures the difference between 2013 (baseline) and 2016 median values of determinants for each intervention in LGs that identified them as priority constraints. These values exclude performance in LGs that did not identify priority constraints in the respective determinants (table 3). Thus, the measurements (figure 7) represent improvement (or otherwise) on identified bottlenecks following development of action plans to address them. While variable levels improvement can be observed in most determinants, geographical access to routine immunisation and antenatal services reduced. This may have resulted from the closure of facilities and dispersal of communities following security challenges in some LGs as identified in table 2.

Figure 8 shows a gap in implementation of activities aimed at addressing bottlenecks. A total of 1562 activities were planned to address identified bottlenecks in the state, in which only $568(36 \%)$ were completely implemented. Only 6 out of 23 LGs fully implemented at least $50 \%$ of planned activities. Implementation gaps occurred across all interventions, however, as shown on table 2 , implementation was not a priority bottleneck with routine immunisation, which is the most government and donor supported intervention.

\section{DISCUSSION}

Our findings reveal that the DIVA model was helpful in identifying bottlenecks and developing evidence-informed action plans to address them. Interpretation of the findings are, however, guided by the understanding that while DIVA is implemented at LG level, these outcomes are measured at state level (which are aggregates of possible effects in all LGs).

Challenges were observed, particularly regarding execution of planned activities to address the bottlenecks.
Funding constraints resulting from poor political will/ government ownership (particularly at the LG level), was identified as a major factor underpinning implementation gaps. These mirror implementation challenges with DIVA in Ghana and Uganda. ${ }^{39}$ In addition to these, data availability to populate the Tanahashi determinants constrained implementation in Uganda. Generally, health systems bottlenecks identified were similar across these countries, save for some context specific constraints discussed below.

Human resources for health was identified as the most constrained determinant across all interventions except routine immunisation where it ranked second to quality. Common human resource challenges identified by the LG teams include weak capacity to deliver the interventions as well as poor motivation and commitment of frontline workers to service delivery. In addition to funding and management constraints, this may have contributed significantly to the poor quality of services which ranked second. In some LGs skilled human resources, where available, were inequitably distributed (being concentrated in larger urban or semi-urban facilities).

Geographical access and availability of commodities were the least constrained determinants identified. Security challenges (including terrorism and ethno-religious conflicts) constrained geographical access to services (particularly immunisation and IMCI) in some communities. Whereas Kaduna is not known as a hotspot for terrorism, findings from this research have shown that isolated security challenges have significant effects on the health system. Most responses to terrorism (including health sector) are currently concentrated in the NorthEastern states of Adamawa, Yobe and Borno. Consequently, there is need for a more widespread assessment 
Table 3 Local governments that identified priority constraints in the respective determinants for each intervention in 2013 (n [\%])

\begin{tabular}{|c|c|c|}
\hline Intervention & Determinants & $\begin{array}{l}\text { Number } \\
\text { of LGs } \\
\text { identifying } \\
\text { bottlenecks } \\
\text { (n [\%]) }\end{array}$ \\
\hline \multirow[t]{6}{*}{ Immunisation } & Commodities & $4(17 \%)$ \\
\hline & Human resources & $13(57 \%)$ \\
\hline & Geographical access & $5(22 \%)$ \\
\hline & Initial utilisation & $2(9 \%)$ \\
\hline & Continuity & $7(30 \%)$ \\
\hline & Quality & $15(65 \%)$ \\
\hline \multirow{6}{*}{$\begin{array}{l}\text { Integrated } \\
\text { management of } \\
\text { childhood illnesses }\end{array}$} & Commodities & $1(4 \%)$ \\
\hline & Human resources & $20(87 \%)$ \\
\hline & Geographical access & $1(4 \%)$ \\
\hline & Initial utilisation & $2(9 \%)$ \\
\hline & Continuity & $12(52 \%)$ \\
\hline & Quality & 9 (39\%) \\
\hline \multirow[t]{5}{*}{ Antenatal care } & Human resources & $22(96 \%)$ \\
\hline & Geographical access & $1(4 \%)$ \\
\hline & Initial utilisation & $2(9 \%)$ \\
\hline & Continuity & $5(22 \%)$ \\
\hline & Quality & $16(70 \%)$ \\
\hline \multirow{5}{*}{$\begin{array}{l}\text { Skilled birth } \\
\text { attendance }\end{array}$} & Commodities & 2 (9\%) \\
\hline & Human resources & $21(91 \%)$ \\
\hline & Initial utilisation & $16(70 \%)$ \\
\hline & Continuity & $5(22 \%)$ \\
\hline & Quality & $2(9 \%)$ \\
\hline
\end{tabular}

LG, local government.

and response to the effects of terrorism and conflicts in Nigeria beyond the known hotspots.

Inequitable siting of health facilities was also cited as a constraint. A well-known reason for this is the tendency for politicians to influence the siting of developmental projects (including health facilities) based on quest for political capital as against equity needs of the population.

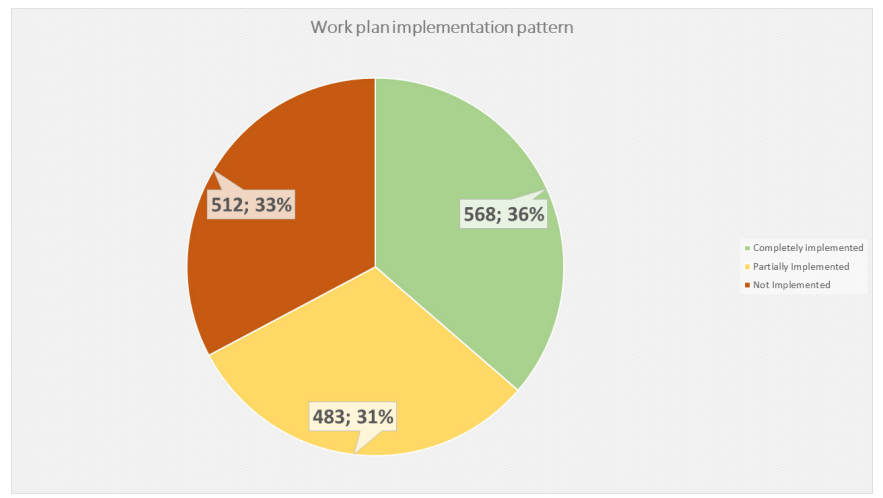

Figure 8 Implementation of planned activities.
Thus, while health services are relatively inaccessible to some communities, others with greater political influence have more facilities than needed even though many of these function sub-optimally. ${ }^{8}$

Utilisation of services was mainly constrained by demand side factors such as sociocultural norms and poorly functional community development committees (which are supposed to provide a link between facility managers and the users of services). Efforts have been made by the national government to revitalise these committees through community Participatory Learning and Action programmes, ${ }^{40}$ however a more sustainable framework for operationalising these committees will require states and LGs to play more significant roles in engaging communities in recognition of their vital role as part of the health system. ${ }^{6}$ Studies in Kenya, Tanzania and Nigeria have shown that communities can play active roles in service delivery and project implementation, health promotion and advocacy and resource mobilisation and management. ${ }^{41-43}$

Planned actions to tackle these bottlenecks mostly revolved around advocacy and community mobilisation, indicating that majority of the solutions were beyond the immediate responsibility or capacity of the LG health teams. This probably explains the weak implementation of planned activities. Across all interventions, improvement in human resources was minimal even though it was the most constrained determinant. The challenges with human resources for healthcare are not new in Nigeria. However, most efforts to address them have focused on increasing their numbers and distribution, particularly Community Health Extension Workers. ${ }^{44}$ This approach is not unusual in LMICs given that maldistribution and high attrition rates are common human resource challenges in these countries. ${ }^{45}$ For example, maldistribution of health workers following punitive transfers and lobbying for posting are common concerns that have affected equitable access of clients to services in India, Pakistan, Mali and Kenya, which staff audits and re-distribution have attempted to solve. ${ }^{33-36}$ In addition to these, our findings suggest that attention should also be given to the capacity of available health workers to deliver specific services effectively. Thus, it is not sufficient to have adequate cadre of staff, efforts should be made to ensure these frontline workers get trained and retrained on the various PHC interventions to ensure quality. Clinical mentoring has also been employed successfully in Malawi, Uganda and Tanzania to strengthen human resource capacity. ${ }^{9}$

Availability of commodities was the most improved determinant even though it was among the least determinants cited as constrained. This pattern probably indicates skewness in implementation of operational plans as government and donors may prefer to intervene in this determinant to sustain supplies as against human resources, which require high costs and locally sensitive training. Availability of commodities was not identified as major constraint for ANC. Furthermore, there was 
improvement in IMCI geographical access in the LGs that identified it as being a bottleneck. The reverse was the case with ANC and routine immunisation where access worsened. This may have been due to insecurity which led to closure of some health facilities in some LGs. These two interventions were probably more affected because they also include community-based outreach services, which declined as reported by participants.

Whereas some indicators for interventions like malaria and routine immunisation (which have strong donor support) improved, ANC indicators slightly declined. This may indicate that managers skew implementation towards donor interests by not prioritising other less supported interventions like ANC. Consequently, action plan implementation tends towards verticalisation contrary to the design of DIVA.

The PHC reviews are yet to be fully institutionalised as implementation is largely dependent on external support and contextual factors such as security, financing and political will. The successful implementation of the Verify-Adjust phase is hinged on a strong monitoring and evaluation system. However, our findings reveal that this system is weak, as reported in previous studies. ${ }^{7}$ Integrated supportive supervision has been relatively stronger with vertical programmes like malaria and HIV/AIDS due to donor funding requirements. ${ }^{46}$ Although donor support has contributed to strengthening health systems in LMICs and improving PHC services in some cases, concerns have been raised about their negative impact on integrated systems strengthening. ${ }^{47}$ For example, increase in HIV/ AIDS funding has been observed to stagnate funding for reproductive health. Further, accusations have arisen that scarce personnel are being drawn off other health services by offers of better-paying opportunities in HIV/ AIDS programmes. ${ }^{47} 48$ We thus recommend a robust government coordination of PHC to improve the effectiveness of DIVA.

While many of the findings are not new, particularly as relates to human resources for health being a major health system challenge in LMICs, including Nigeria, ${ }^{8445}$ the PHC review presents a new approach to evidence-informed solutions using DIVA. Successful implementation of DIVA is guided by four principles - strong government leadership and ownership; flexible and adaptable to local programmes, building on what exists; community involvement and engagement and supportive (technical and financial) process from civil society, private sector and development partners. ${ }^{11}$ Whereas, Nigeria's integrated governance structure may have played an important role in sustaining implementation to date, ${ }^{7}$ dependence on donors as primary technical and funding sources for implementation may threaten future sustainability of the initiative.

A limitation of our study is that the magnitude of change observed may not reflect the magnitude of impact DIVA has on health system performance. This is because DIVA implementation is at the LG while this study aggregates findings to state level, consequently, outstanding results from high performing LGs are potentially obscured by low performing ones. However, given that our study focuses on state-level effectiveness of implementing the model (as against efficacy or impact evaluation), our findings are reflective of the potential of DIVA to improve health system performance within a decentralised context. Further, our analysis utilised median values as against means, thus eliminating the effect of possible extreme values from some LGs. While the use of routine data may be considered a limitation of DIVA owing to data quality concerns, our study focuses on change in coverage as against actual coverage thus potentially eliminating some known quality deficits. For example, the denominators for coverage in routine data are based on expected values projected from Nigeria's last census in 2006, but observed coverages sometimes exceed $100 \%$ signifying a possible change in population dynamics over the past 10 years. However, this is unlikely to affect our findings as we analyse changes in coverage rather than the absolute coverage. Further, Nigeria's electronic routine data platform and the PHC bottleneck analysis tool possess internal quality control mechanisms. ${ }^{24}$

This study uses an uncontrolled before and after design for assessing change in identified bottlenecks. Consequently, it is constrained in attributing observed improvement to the intervention. This design was, however, most suitable given that all LGs in the state are implementing DIVA. Using LGs in other states as controls will potentially introduce complex confounders given the dissimilarities in contexts, governance and other characteristics across states. However, the time series charts used in analysing health system outcomes support the interpretation of our findings. Further, a follow-up evaluation of contextual influences on DIVA outcomes using the Model for Understanding Success in Quality has been conducted to develop a theory of attribution that takes into account other factors. ${ }^{20}$

We found this design very useful and easy-to-use for lower level operational managers in LMICs implementing/evaluating health system improvement initiatives, particularly in district/decentralised health systems. Although desirable, we were unable to get sufficient reliable data to conduct a time series analysis for facility deliveries as proxy outcome indicator for skilled birth attendance due to gaps in routine data collection. As with all participant observation research, this study is prone to the Hawthorne effect. However, given that this is an embedded real-world continuous improvement intervention, the Hawthorne effect is a desirable as part of the intervention if positive and sustained.

\section{CONCLUSIONS}

Our study demonstrates that PHC planning using the DIVA approach model can potentially improve performance in decentralised health systems like Nigeria's if implemented well. However, effective implementation will require some degree of central oversight and ownership. 
While an integrated approach to improving health system performance is ideal, this may not always be practicable owing to the complexity of the health system. However, our study has shown that integrated planning and some aspects of implementation are possible and potentially effective if structural and managerial bottlenecks are addressed. We view that while integrated financing structures recommended by Nigeria's ongoing PHC under one roof reforms policy may improve effectiveness of DIVA, political considerations have constrained its implementation to date. ${ }^{46}{ }^{49}$ However, to improve health systems performance, a governance model that empowers the LGs technically, politically and financially will have to evolve, requiring the engagement of stakeholders at different levels of government as well as different sectors of the economy given that most challenges to performance observed are outside the immediate jurisdiction of the LG health authorities. This inference is supported by our follow-up context and process evaluations of DIVA implementation. ${ }^{2026}$

We recommend the tools used in this study (S1) for real time diagnosis, improvement and evaluation of health systems performance when implementing this model.

\section{Author affiliations \\ ${ }^{1}$ Department of Planning, Research and Statistics, National Primary Healthcare Development Agency, Abuja, Nigeria \\ ${ }^{2}$ Centre for Health Policy, School of Public Health, University of the Witwatersrand, Johannesburg-Braamfontein, South Africa \\ ${ }^{3}$ Gillings School of Global Public Health, University of North Carolina at Chapel Hill, Chapel Hill, North Carolina, USA \\ ${ }^{4}$ Epidemiology and Biostatistics Division, School of Public Health, University of Witswaterstrand, Johannesburg, South Africa \\ ${ }^{5}$ Research Unit, Nigerian Institute of Medical Research, Lagos, Lagos, Nigeria ${ }^{6}$ Department of PHC Systems, National Primary Healthcare Development Agency, Abuja, FCT, Nigeria \\ ${ }^{7}$ School of Geography and Earth Science, McMaster University, Hamilton, Ontario, Canada}

Acknowledgements We acknowledge the support (including permission to use data) of Nigeria's National Primary Healthcare Development Agency and the Kaduna State Primary Healthcare Development Agency, Nigeria. Mr Usman Garba of UNICEF Nigeria is acknowledged for his support with respect to data availability. The School of Public Health, Faculty of Health Sciences, University of the Witwatersrand, Johannesburg, South Africa is also acknowledged for its support.

Contributors EAE designed and carried out the study (coached participants, collected and analysed data) and prepared the first draft of the paper. EAE and $\mathrm{NI}$ were embedded researchers. NN and JE contributed to the design of the protocol and supervised the study. NN, RR, LI, NI and JE contributed to data analyses, interpretation/discussion of findings, developing and revising the final manuscript. All authors approved of the final manuscript.

Funding This work has been funded by TDR, the Special Programme for Research and Training in Tropical Diseases, which is hosted at the World Health Organization and cosponsored by UNICEF, UNDP, the World Bank and WHO (TDR grant number: B40299). First author ORCID iD: 0000-0001-8277-2570. JE and EAE are also supported by South Africa's National Research Foundation Research Chair's program (SARChl). The funders had no role in study design, data collection and analysis, decision to publish or preparation of the manuscript.

Competing interests None declared.

Patient consent for publication Not required.

Ethics approval Ethics approval for this study was obtained from the National Health Research Ethics Committee of Nigeria (NHREC/01/01/2007-13/08/2016) and the Human Research Health Ethics Committee of the University of the
Witwatersrand, South Africa (M161122). Informed consent (written) was received from all respondents. Permissions were obtained from the NPHCDA for use of data not in public domain.

Provenance and peer review Not commissioned; externally peer reviewed.

Data sharing statement The data set from this study are available at the National Primary Healthcare Development Agency (NPHCDA), Abuja, Nigeria, but restrictions may apply to the availability of these data, which were used with permission for the current study, and so are not publicly available. Data are however available from the authors upon reasonable request and with permission of NPHCDA. Materials used for data collection are presented here as supplementary files.

Open access This is an open access article distributed in accordance with the Creative Commons Attribution Non Commercial (CC BY-NC 4.0) license, which permits others to distribute, remix, adapt, build upon this work non-commercially, and license their derivative works on different terms, provided the original work is properly cited, appropriate credit is given, any changes made indicated, and the use is non-commercial. See: http://creativecommons.org/licenses/by-nc/4.0/.

\section{REFERENCES}

1. Stigler FL, Macinko J, Pettigrew LM, et al. No universal health coverage without primary health care. The Lancet 2016;387:1811.

2. London School of Hygiene and Tropical Medicine. In: Black N, Gruen $\mathrm{R}$, Low and middle income countries: from colonial inheritance to primary care," in understanding health services. Berkshire: Open University Press, 2005:166-77.

3. Ramaswamy R, Iracane S, Srofenyoh E, et al. Transforming maternal and neonatal outcomes in tertiary hospitals in ghana: an integrated approach for systems change. J Obstet Gynaecol Can 2015;37:905-14.

4. NIH. Strategic health planning: guidelines for developing countries. Leeds: Nuffield Institute for Health, University of Leeds, 2002.

5. Mburu FM. Health delivery standards: vested interests in health planning. Soc Sci Med 1994;39:1375-84.

6. Abimbola S, Negin J, Jan S, et al. Towards people-centred health systems: a multi-level framework for analysing primary health care governance in low- and middle-income countries. Health Policy Plan 2014;29:ii29-39.

7. Eboreime EA, Abimbola S, Obi FA, et al. Evaluating the sub-national fidelity of national initiatives in decentralized health systems: integrated primary health care governance in Nigeria. BMC Health Serv Res 2017;17:227.

8. Eboreime E, Abimbola S, Bozzani F. Access to routine immunization: a comparative analysis of supply-side disparities between Northern and Southern Nigeria. PLoS One 2015;10:e0144876.

9. Vasan A, Mabey DC, Chaudhri S, et al. Support and performance improvement for primary health care workers in low- and middleincome countries: a scoping review of intervention design and methods. Health Policy Plan 2017;32:437-52.

10. Althabe F, Bergel E, Cafferata ML, et al. Strategies for improving the quality of health care in maternal and child health in low- and middleincome countries: an overview of systematic reviews. Paediatr Perinat Epidemiol 2008;22:42-60.

11. UNICEF;MSH. "The guidebook: strengthening district management capacity for planning, implementation and monitoring for results with equity,". New york: UNICEF, 2012.

12. Durlak J. "The importance of quality implementation for research, practice and policy,". ASPE U.S: Department of Health and Human Services, 2013.

13. O'Connell T, Sharkey A. "Reaching universal health coverage through district health system strengthening: using a modified tanahashi model sub-nationally to attain equitable and effective coverage,". UNICEF: New York, 2013.

14. Kim SY. Efficacy versus effectiveness. Korean J Fam Med 2013;34:227.

15. Haynes B. "Can it work? Does it work? Is it worth it? The testing of healthcareinterventions is evolving.,". BMJ 1999:319.

16. WHO. "World report on health policy and systems research,". Geneva: World Health Organization, 2017.

17. NPHCDA. "Introduction to ward health system: briefing package for sensitization on the ward health system,". Abuja, Nigeria: National Primary Health Care Development Agency, 2006.

18. WHO. "WHO called to return to the declaration of Alma-Ata,". http:// www.who.int/social_determinants/tools/multimedia/alma_ata/en/ (Accessed 27th Sep 2017).

19. NPHCDA. National guidelines for the development of PHC system in Nigeria. 4th ed. Abuja, 2012. 
20. Eboreime EA, Nxumalo N, Ramaswamy $R$, et al. Strengthening decentralized primary healthcare planning in nigeria using a quality improvement model: how contexts and actors affect implementation. Health Policy Plan 2018;33:715-28.

21. NPC. Population and housing census of the federal republic of nigeria: national and state population and housing census priority tables. Abuja: National Population Commission, 2006.

22. FMOH. Directory of Health Facilities in Nigeria. Abuja: Federal Ministry of Health, 2012.

23. Institute for Healthcare Improvement. Science of improvement (IHI), "How to improve," IHI. 2011 http://www.ihi.org/resources/ Pages/Howtolmprove/ScienceoflmprovementHowtolmprove.aspx (Accessed 28 Feb 2017).

24. NPHCDA. "Guidelines for the training of resource persons and implemantation of quarterly primary health care planning \& implementation review: bottleneck analysis methodology,". Abuja: National Primary Health Care Development Agency, 2012.

25. Tanahashi T. "Health service coverage and its evaluation,": Bulletin of Wold Health Organization, 1978:295-303

26. Eboreime EA, Eyles J, Nxumalo N, et al. Implementation process and quality of a primary health care system improvement initiative in a decentralized context: a retrospective appraisal using the quality implementation framework. Int J Health Plann Manage 2018;24.

27. Hogwood B, Gunn L. Policy analysis for the real world. Oxford: Oxford University Press, 1984.

28. Lipsky M. Street-level bureaucracy: dilemmas of the individual in public service: 30th Anniversary Expanded Edition, Russel Sage Foundation, 2010.

29. Sabatier P, Mazmanian D. The conditions of effective implementation: a guide to accomplishing policy objectives. Policy Anal 1979:5:481-504.

30. Kiwanuka Henriksson D, Fredriksson M, Waiswa P, et al. Bottleneck analysis at district level to illustrate gaps within the district health system in Uganda. Glob Health Action 2017:10:1327256.

31. Sigma iS. "Determine the Root Cause: 5 Whys," i Six Sigma. https:// www.isixsigma.com/tools-templates/cause-effect/determine-rootcause-5-whys/ (Accessed 28th Feb 2017).

32. NPHCDA. "Institutionalization of the primary health care reviews in Nigeria: status and progress,". Abuja: National Primary Health Care Development Agency, 2013.

33. Shorten A, Smith J. Mixed methods research: expanding the evidence base. Evid Based Nurs 2017;20:74-5.

34. Cheetham M, Wiseman A, Khazaeli B, et al. Embedded research: a promising way to create evidence-informed impact in public health? J Public Health 2018:40:i64-i70.

35. Vindrola-Padros C, Pape T, Utley M, et al. The role of embedded research in quality improvement: a narrative review. BMJ Qual Saf 2017;26:70-80.
36. DeWalt K, DeWalt B, Wayland C. Bernard H, "Participant observation," in handbook of methods in cultural anthropology. Walnut Creek, CA: AltaMira Press, 1998:259-99.

37. Howell JT. Hard living on clay street: portraits of blue collar families, prospect heights. Waveland Press, Inc: Illinois, 1972.

38. NPHCDA. "Assessment of NSHDP Progress, Status and Indicators through PHC reviews: mission report,". Nigeria, Abuja: National Primary Health Care Development Agency, 2012.

39. Yawson AE, Bonsu G, Senaya LK, et al. Regional disparities in immunization services in Ghana through a bottleneck analysis approach: implications for sustaining national gains in immunization. Arch Public Health 2017;75.

40. National Primary Health Care Development Agency. "Annual report of the national primary healthcare development agency,". Abuja: NPHCDA, 2013.

41. Abimbola S, Molemodile SK, Okonkwo OA, et al. 'The government cannot do it all alone': realist analysis of the minutes of community health committee meetings in Nigeria. Health Policy Plan 2016;31:332-45.

42. Frumence $\mathrm{G}$, Nyamhanga $\mathrm{T}$, Mwangu $\mathrm{M}$, et al. Participation in health planning in a decentralised health system: Experiences from facility governing committees in the Kongwa district of Tanzania. Glob Public Health 2014;9:1125-38.

43. Goodman C, Opwora A, Kabare M, et al. Health facility committees and facility management - exploring the nature and depth of their roles in coast province, Kenya. BMC Health Serv Res 2011;11:229.

44. Abimbola S, Okoli U, Olubajo O, et al. The midwives service scheme in Nigeria. PLoS Med 2012;9:e1001211.

45. Abimbola $\mathrm{S}$, Olanipekun $\mathrm{T}$, Schaaf $\mathrm{M}$, et al. Where there is no policy: governing the posting and transfer of primary health care workers in Nigeria. Int J Health Plann Manage 2017;32.

46. NPHCDA, HERFON, UNICEF. PACT and SCI, "Primary health care under one roof implementation scorecard iii report. 2015.

47. Ejughemre U. Donor support and the impacts on health system strengthening in sub-saharan africa: assessing the evidence through a review of the literature. Am J Public Health Res 2013;1:146-51.

48. Yu D, Souteyrand Y, Banda MA, et al. Investment in HIV/AIDS programs: does it help strengthen health systems in developing countries? Global Health 2008;4:8.

49. Anyene B. "Sustainable immunisation financing: what can africa do?,". Developement Diaries 2016.

50. FMOH. "National health policy,". Nigeria, Abuja: Federal Ministry of Health, 2017

51. World Health Organization. Pregnancy, childbirth, postpartum and newborn care: a guide for essential practice. World Health Organization: Geneva, 2003. 